\title{
THE FEDERATION FOR INTERNATIONAL REFRACTORIES RESEARCH AND EDUCATION (FIRE): PROGRESS AND OUTCOME ON EDUCATION, RESEARCH AND INDUSTRIAL PARTNERSHIP
}

\author{
RIGAUD, Michel \\ Ecole Polytechnique, Campus University of Montreal \\ Montreal, Qc, H3C 3A7, Canada \\ michel.rigaud@polymtl.ca
}

Keywords: Refractory research, refractory education, outsourcing, crowdsourcing, FIRE

\begin{abstract}
FIRE has been incorporated as a non-profit organization in Canada, in May 2005. It is by now a network of professors, researchers and industrial partners, representing eight different universities spread in six different nations and eleven multinational companies, who have gathered, to undertake well-defined precompetitive research projects, and to train highly-qualified personnel for the industry.

The evolution of the refractory education arena, in an economically globalized world, caught in a maelstrom of technical changes, is presented. The changes of paradigm from the "information age society" to the "crowdsourcing" in background, the FIRE realization are highlighted in such a context of "conceptual age society" are considered, with the concept of "coopetition".
\end{abstract}

\section{Introduction}

Already at the end of the last century, it was clearly perceived that the refractory engineering education would have to be re-appreciated rapidly, at least in the Western World. Several authors had expressed their concerns about the fast de-valorization of its presence in many engineering faculties [1-4], along with several other specialties, like mineralurgy, geology, metallurgy, as distinct engineering programs. It was of course the sign of big changes taking place, at all level, in our societies which corresponded to delocalization of many mass-production heavy industries which took place this past 20 years. These changes were made possible with the advent of new technological innovations (in computation and communications) and with more accurate environmental concerns. All those events made it possible and more profitable to outsource many operations in yet to be developed countries.

On the same line, hundreds of pages have been published to illustrate how the multiplication of the business exchanges (translated into the word: "globalization") imparted the economic growth and caused a huge increase of the financial markets. Hence, the manufacturing industry in Western countries, including of course the refractory industry has been affected as well as the world of engineering education as a whole, including the refractory engineering education. The fact is that the delocalization of many industrial sectors, moving from the USA, Europe and Japan to the BRIC Cluster of Countries (Brazil, India, Russia and China) and hence the rapid growth of the heavy industries in these later countries, have brought about changes in cascades.

To review those changes is not the purpose of this paper but it is necessary to insist upon the fact that many of these changes have been propelled by an explosion in the technology transfer rates, supported by the computer industry and the individuals with logical, linear computer-like capabilities, making that delocalization easier to follow. As a result, the concentration in decision making, the conceptualization of business on how to solve the organizational problems, how to cope with political and judiciary decision centers, how to control innovations and generate sources of knowledge have created constraints not only on the refractory industry but also on the education world. New skills had to be learned, then taught and learned by many more. In front of those changes, the engineering faculties had to choose between teaching fundamental and applied matters, between more mathematics and less craftsmanship, adding the rudiments of the management of 
social and environmental concerns as well as of engineering economy and business laws. Too much to teach!

Too much to teach, less attraction towards many traditional programs too closely linked to heavy-stack industries, more on nano-bio-ecological sciences, on computers and new engineering programs (biomedical, pharmaceutical, environmental, robotics, etc...). No surprised hence if the refractory engineering program have been evacuated from the undergraduate curriculum in so many engineering faculties.

The purpose of this paper is then to describe how the Federation for International Refractories Research and Education has been created to confront the situation. It is divided into three main parts to answer three questions: What are now the challenges to be met by the educators devoting their career to train refractory engineers? How FIRE has been organized to face those challenges? What have been the outcomes since 2006? To conclude, in the last section of this paper, some of the challenges to be met by the refractory industry are considered, to cope with the outsourcing issue in research and the need to work in coopetition.

\section{The challenges defying the refractory educators in universities today}

The first challenge is to avoid overlooking all the on-going changes in our society: we are not yet over with the globalization trend but already we have to cope with the signals that our present-day "information age society" is changing to a "conceptual age society" and that "outsourcing" is being challenged by "crowdsourcing". The fact that we are now entering in a new age, and moving from an economy and a society built on the logical, linear, computer-like capabilities of the "Information Age" to an economy and a society built on the inventive, empathic, big-picture capabilities of what's rising in its place, the "Conceptual Age", was already signalled in [5] and [6]. The exponential growth of know-how brought about by the convergence of numerical solutions and means of communications, have allowed the financial wizards and the higher management of conglomerates to mastermind the innovation process and to multiply the occasions for more and more outsourcing. As a result of all convergences in communication means now comes "crowdsourcing" [7]. "Crowdsourcing" is to be viewed as the power of many can be leverage to accomplish feats that were once the responsibility of a specialized few. This aspect will also be tackled in Section V.

In that context, the new paradigm for education to adopt will be to exercise both sides of the individual's brain; the left side (the locus of the logos, and the rationality), the right side (the locus of emotions, and imagination) for a better match between logics and practical experiences, rigor and creative thinking. The engineering students will have to learn to implement changes to become efficient in not only the technical production (as it was in the traditional curriculum), but also in the organizational and economical arenas (expected from the new curriculum) and hopefully efficient in the ethical issues (to come in the more advanced curriculum of tomorrow). The engineers will still have to master the laws and the rules of sciences (the principles) and engineering (the methods) but will also have to understand the social needs and modes of distribution and exchanges in the business world, all to be governed by moral values.

In that perspective, many North American engineering faculties have already geared themselves to readjust their programs and to adopt the so-called CDIO Approach: "to ConceiveDesign-Implement-Operate either value added engineering products or processes and systems, in multinational team-based environment" [8]. For many educators, with "new insights coming from innovation theory, coupled with changes in the societal use of technology, that imply growing complexity, and a need for social skills", [8] the needs to adjust the overall engineering education to "broaden the scope and shift the focus from technological development and breakthroughs to a broaden focus on market demands, strategic planning issues and technological forecasting" [8]. Hence refractory education have now to adjust, realizing the graduates in refractory are to promote the business interests of the of the refractory industry with the required competencies necessary to manage the creative, socio-technical and design skills needed. The aspect will be also considered in Section V. 
Hence, to train culturally-efficient refractory engineers, education will have to create an environment where the students will be able to learn materials and refractory technology in an economical, ecological and ethical context, in order to understand the business and cultural issues the industry is facing. To cope with many challenges, new forms of collaboration between the refractory industrialists and academics (those remaining) are to be invented.

For this to happen, it would then be appropriate for the refractory industry to promote itself as advanced, as nano-, as bio-, as eco-, as any other industrial sectors. This can be done with the concerted efforts of its business leaders and its most enthusiastic academics. So the refractory industry has to be more aggressive to escape to its syndrome of the "hidden industry".

The refractory educators have to work hand in hand with the refractory industrialists to capture its proper share of the collective funds allocated, to both the education system and research system, by granting agencies of all kinds. The precedents being implemented in Germany and France specifically for refractories and which have been described by [9] and [10] are to be considered seriously.

In this paper by M. Huger [9], one will learn how since 1998, the Sorbonne/Bologna process, in which 30 European states are currently involved, has aimed to establish an European Higher Education Area, and how some Engineering schools in France have adjusted to educate young engineers at the Master and Doctoral level in the refractory field, backed up by granting agencies to fund national research programs in refractories, under such acronyms as "Prometeref", "Druide" and "Norev". While in Germany, in October 2009, the Koblentz University of Applied Science, an endowed professorship was solemnized for refractory materials and presented to Dr. Olaf Krause. A year before, in April 2008, the German Research Foundation approved a six-years project, starting in March 2009, on Refractories Initiation for Low Emissions, grouping 10 German Universities under the coordination of Freiberg University [10]. In 2010, the German Institute for Refractories and Ceramics is moving in its new facility in Höhr-Grenzhausen, a new center to promote refractories research. Let us examine now what's Fire has accomplished along such lines.

\section{The FIRE organization}

The Federation has been set up to promote refractory education in engineering faculties, at the graduate levels of Master and Doctoral degrees (rather than at the undergraduate level). The Federation was first incorporated as a non-profit organization, in Canada, in May 2005, as a network of academic institutions, including at present eight institutions from six different countries, and eleven multinational companies to develop refractory education worldwide, and to be able to recruit and to train well-educated refractory engineering, with an international vista. FIRE members are listed in Table 1. The by-laws and rules of the organization can be found on the FIRE website at [http://www.polymtl.ca/fire].

Other details on its organization and evolution have been published since the real start of its activities in September 2006. [11][12]

FIRE does not deliver any academic diploma, only certificates to recognize and sanction students' results, after completion of a degree, as a master of applied sciences and/or of a Ph.D. program, in a FIRE academic institution. The minimum requirements to be met for the issuance of FIRE's certificates are the following:

I. The program of study for students must incorporate a training period in at least one FIRE network campus, other than the alma-mater.

II. The program of study for the students must be duly sanctioned by the academic institution to which they belong, in accordance with the local university requirements.

FIRE recognizes only students who belong to one of the FIRE's academic poles. The teaching of courses and the research programs are to be accredited by FIRE, duly approved by all the institution, as listed on the FIRE website. All activities are conducted in English, but the 
students have to be at least bilingual. Since all FIRE students are graduates students, they do perform research under the guidance of two co-directors of research from two different institutions and in line with one of the 3 FIRE pre-approved research programs, which have been established since September 2007, by the FIRE Board Members.

Hence FIRE is a collaborative entity, not a brick and mortar one. It is a real outsourcing network, a multi-investigators group with more than 35 research associates, not counting the students, to conduct pre-competitive research programs for the refractory industry. In so doing, the Federation hopes to raise the profile of the refractory engineering education among the peers in the academic and industrial community, so as to be perceived as a valuable venue for the engineering students to specialize in. FIRE does grant to all of its registered students a travel fellowship to cover their costs of travelling and lodging, when they study on a campus, which differs from their almamater, where they belong.

\section{Some FIRE outcomes since 2006}

\section{IV.1 Education Programs}

As of April 2010, FIRE has delivered 15 certificates (14 to Master students, 1 to a Ph.D. student) and 11 students are presently on board, 6 of who will have fulfilled all requirements to obtain an M.Sc. Degree, in October 2010, and 5 other still engage in their Ph.D. program. In total, FIRE has already granted 32 fellowships, since six students among the 26 have already undertaken more than one exchange (M.Sc. and Ph.D.). So far, the first 15 FIRE graduate students have presented 21 technical reports to the FIRE members and contributed to 41 published papers in the open literature. In 2009, one of the FIRE students (Mariana Braulio) has received two international recognitions for her work: the Wakabashi Prize from TARJ in Japan, and the Eirich Prize, from the GRA, in Germany [13][14].

All FIRE graduates have their CV listed on the FIRE website, annually updated. From there, it is an easy task to follow the exchanges that have been organized between Austria, Brazil, France, Germany, the Netherlands and Japan. One other dimension worth mentioning is that when students are traveling in another country, they have the opportunity to work not only in another academic institution, which has been selected, but also in a FIRE "user of refractories" research facility, to familiarize them to the industrial world since the stage has to be accepted to fit with the academic rules set by their own university and with FIRE rules on coopetition, to avoid any conflict of interest.

\section{IV.2 Research Programs}

Since September 2007, a first 3-year plan has been defined and all research projects carried out by the FIRE students have to fit in within one of three themes:

- The thermomechanical behavior, modeling and testing of refractories

- The thermochemical behavior, simulation and testing of refractories

- The design of residual expansion with engineered microstructure of alumina-magnesiabased castables

The goals, the objectives and principal milestones for those themes of research have been defined and accepted by all FIRE members. The pursuit of the objectives, which are set for each sub-project, is coordinated by one team leader for each theme. The results are regularly presented to the FIRE members according to an accepted schedule, among the participants. Not all of the FIRE members are informed annually of all the results obtained, at the annual FIRE Board Members meeting and those results are gathered in Annual Reports of Activities distributed to all members.

The objectives of themes 1 and 2 are to concentrate on the aspects of testing both the thermomechanical and thermochemical properties of the refractories. To coordinate all the efforts, the main refractories, which are to be tested, are different types of commercial alumina-magnesia bricks and castables, commonly used in steelmaking ladles. In project one, the main characteristics 
measured are the Young modulus, the modulus of rupture and the fracture energy as a function of temperatures, measured with different methods and different specimen preparation techniques. The aim is to harmonize the data and understand the meaning of the different values gathered. Along this line, new fracture tests that investigate multi-axial compressive failure are being developed. Always in project one, the modeling is targeting on the thermomechanical behavior of insulated and non-insulated ladles, and special efforts are being undertaken to develop the proper modeling technique to understand the joint behavior in refractory linings, a very practical point and worthwhile to master.

In project two, different corrosion laboratory setups are being evaluated, at different institutions in the FIRE network, and compared. All efforts here are also concentrated on aluminamagnesia refractories, for steel ladle linings applications. The priority is to acquire and improve knowledge concerning:

- The validity of the thermodynamic calculations, the improvement of the data bases and the calculation protocol.

- The importance of taking on account the kinetic aspects, including the fluid dynamics, the volatility of the species and the inter-diffusion mechanisms, interacting with phase changes.

- The couplings effects between impregnation of slags and vapors, the phase transformation and the mechanical behavior (state of stress-strain of the refractories).

The project 3 is about the engineered microstructure design of alumina-magnesia-based castables to provide a support for novel technological developments in that area. It is to evaluate on a precompetitive basis the influence of the raw materials used, for the aggregates as well as the matrix materials, to achieve designed residual expansion and optimize their thermochemical and thermomechanical properties. Numerous variables are considered such as the nature and amount of micro-silica used; the grain size effects of the magnesia, alumina and spinel used; the nature and amount of hydratable alumina binders; the combination of spinel containing and in-situ spinel forming materials; the nature and amount of nano-scaled particles; the use of mineralizers. All aspects of hydration, rheology and dispersions aspect are being covered and the properties evaluated in each case are the flexural mechanical strength as a function of temperatures, at different temperature levels up to $1500^{\circ} \mathrm{C}$, the sintering behavior, sintering rate and linear expansion, creep resistance, hot modules of rupture at 1150,1300 and $1500^{\circ} \mathrm{C}$, dynamic slag corrosion test evaluation, all backed up with appropriate chemical, SEM-EDS and X-R diffraction analysis. Considering all the results obtained so far, it is already possible to create a road-map to adjust the expansion in within predetermined value: either 1 to $2 \%, 2$ to $3 \%, 3$ to $4 \%$ and even 4 to $5 \%$ if so wish! It is then possible to provide alternatives routes to the expansion target desired, maintaining the desired costs and the overall performances, taking on account various interactions among the variables.

In within each themes 1 to 3 , few other projects are been added as part of a students training, as they are considered of interest to industrial partners, such as the thermomechanical behavior of flexible model materials based on aluminium nitride; the behavior of joints-measurements and simulation on magnesia-carbon bricks; the thermomechanical simulation of ladle pre-heating with and without insulation; and the thermochemical characterization of high-carbon containing refractory castables. All results are communicated to FIRE members, in the form of technical reports. 


\section{$V$. The refractory industry and FIRE new challenges}

As already stated in [12], the FIRE's point of view on Education can be summarized in 3 propositions:

1) To make refractory education programs attractive and to gain visibility in engineering faculty and/or departments, they have to be offered at the graduate level: masters and $\mathrm{Ph}$. D.

2) To seduce graduating engineers from different horizons to embrace a career in the refractory industry, we need to allow them, to acquire an international vista, to work with people of different nationalities, cultural background and ethical values, to learn foreign languages.

3) To surmount the many crises we are confronted with, we do need to search for different answers. We need to make our mea culpa, as educators, having neglected to care about the development of the two sides of the brain of our students; the left and the right, which has led to the hypoplasia (arrested development of an organ, leaving it in an immature state) of the right side.

Then to be practical, FIRE members at the academic level will have:

1) To follow a more systematic approach to pool the resources and the expertise more efficiently to find complementarities, in teaching as well as in research.

2) To imagine ways to multiply the exchanges between the students in every country involved in the network and find means to allow the research associates to also take part in such exchanges.

3) To teach new cutting-edge lectures and to include elective courses on innovation and case studies, forecasting and strategic planning, in an evolving economic, ecologic and ethical context, all related to the refractory industry.

On the Industrial Partnership and Research front, FIRE is considering both outsourcing as well as crowdsourcing. Over the last 15 years or so, outsourcing has changed the relationship between producers of refractories and users of refractories. Now in many cases, the manufacturers of refractories are accepting the responsibility of the installation and maintenance of the refractories. They themselves may outsource those two tasks to others local actors, but the consequences remain the same. Everything has to be planned for faster, cheaper, smarter and easier ways to achieve some pre-set targets of performances. All fringe costs are to be minimized or simply eliminated, included in those, the cost of research, on new materials. To prevent more of the downsizing on research movement to occur, those who remain have to learn to work in this "outsourcing mode" at all levels: the refractory researchers in industries as well as the refractory educators and researchers in universities. The issue again is for the industry to keep the costs associated with innovations to a minimum, and for the academics to keep the costs of education at a level where it can still be attractive to recruit graduate students. One solution FIRE has been advocating is to form a network where each member tries on each others' inputs. The wealth of networking is based on collaboration among individuals that are organized without managerial hierarchies. Their motivations fall into extrinsic and intrinsic categories: Extrinsic: to obtain some extrinsic financial support, and Intrinsic: based on the belief that the educative mission is to enhance human creative labor. But since the game is to play outsourcing in within a network, now comes "crowdsourcing", which some already see as driving the future of business [5].

Yes, crowdsourcing is still in its infancy, but it cannot be ignore and FIRE as a whole has to consider the challenges this may offer. So in this line, FIRE is looking to recruit more usersmembers to enlarge its networks, to achieve a new status and become a much broader outsourcing networking for precompetitive research, in order to reach a size where the network members could be diversified enough, to have the characterizations of a crowd.

So at the industrial level, FIRE will do its best.

1. To induce the industrial users of refractories, from different horizons to join forces with the networks to focus on problems to be solved with the expected new process to be put in 
place, whether it will be related to cost reduction, or to more ecological or sustainable processes, more energy intensive or using less total amount of energy.

2. To find ways, with the academics, to cope with the actualization of the knowledge and reorientation of experienced engineer in the industry, allowing them to benefit from the resources of the network.

3. To contribute to the accumulation and assimilation of knowledge to promote the use of refractories with wisdom.

\section{Acknowledgements}

Thanks are addressed to all FIRE members who believe in its mission, for their dedication and financial contribution, working together for the perenity of the refractory industry, with all the FIRE research associates and FIRE students, since its beginning.

\section{References}

[1] R.C. Bradt et al., "Refractories Education by short courses/seminars" Proceedings, UNITECR 1997, in New Orleans, USA, Ed. By M.A. Strett, pp 1161-1168.

[2] R. Telle, "Education on Refractories in Europe" Proceedings, UNITECR, 2003, in Osaka, Japan, pp 18-21.

[3] M. Rigaud, "Refractory Education in North America" Proceedings, UNITECR 2003, in Osaka, Japan, pp 13-15.

[4] M. Rigaud, "Education and Research: Their Relevance to the Future Prosperity of the Refractories Industry” UNITECR 2005, in Orlando, USA, Ed by [...], pp [...]

[5] D.H. Pink, “A whole New Mind, Why Right-Brainers Will Rule the Future”, Riverhead Books, New York, NY, USA, 2005.

[6] V.C. Pandolfelli and M. Rigaud, "What does seduction have to do with Refractory Engineering Education in the $21^{\text {st }}$ Century" Journal TARJ, Vol. 28, No. 1, 2008, pp 3-7.

[7] J. Howe, "Crowdsourcing” Three Rivers Press, Random House Inc, New York, NY, USA, 2008.

[8] E. Crawley, J. Malmqvist, S. Östhund and D. Brodeur, "Rethinking Engineering Education" Springer Science, New York, NY, USA, 2007.

[9] M. Huger, "Education on Refractories in France" Proceedings, UNITECR 2009, in Salvador, Brazil, (CD-Rom)

[10] C.G. Aneziris, "Education and Research of Refractories in Germany" Proceedings, UNITECR, 2009, in Salvador, Brazil, (CD-Rom)

[11] S. Pirker, C. McFarlane and M. Rigaud, "FIRE - The Federation for International Refractory Research and Education” RHI Bulletin, No. 1, 2006, pp 43-45.

[12] M. Rigaud, “FIRE: Still Growing” Proceedings, UNITECR, 2007, in Dresden, Germany, pp 102-105. 
[13] M. Braulio, L.R. Bittencourt, J. Poirier and V.C. Pandolfelli, "Micro-silica Effects on CementBonded Alumina-Magnesia Castables” Journal TARJ, Vol. 28, No. 3, pp 180-184, 2008.

[14] M. Braulio, L.R. Bittencourt, S.R.Van der Laan and V.C. Pandolfelli, "Novel Engineered Routes for Advanced $\mathrm{Al}_{2} \mathrm{O}_{3}-\mathrm{MgO}$ Refractory Castables", in Refractory World Forum, in 2010. 